\title{
Genetic Variability, Heritability and Expected Genetic Advance in Soybean [Glycine max (L.) Merrill] Genotypes
}

\author{
Besufikad Enideg Getnet \\ Department of Plant Sciences, Gambella University, Gambella, Ethiopia \\ Email address: \\ besuloza@gmail.com \\ To cite this article: \\ Besufikad Enideg Getnet. Genetic Variability, Heritability and Expected Genetic Advance in Soybean [Glycine max (L.) Merrill] Genotypes. \\ Agriculture, Forestry and Fisheries. Vol. 7, No. 5, 2018, pp. 108-112. doi: 10.11648/j.aff.20180705.12
}

Received: October 27, 2018; Accepted: November 13, 2018; Published: December 28, 2018

\begin{abstract}
Information on the extent and pattern of genetic variability, heritability, and genetic advance under selection are essential to design breeding strategies in the available germplasm of soybean and helps to identify elite genotypes that will be incorporated in to soybean crop improvement programs to address the growing demand of the crop in Ethiopia. Forty-nine soybean (Glycine max (L.) Merrill) genotypes were evaluated in a field study in $7 \times 7$ simple lattice design with two replications at Jimma Agricultural Research Center (JARC) with the objective of estimating genetic variability, heritability, expected genetic advance, and to estimate genetic divergence, thereby, to cluster the test genotypes in to genetically divergent classes. The result indicated substantial variations for all the traits evaluated. Analysis of variance revealed that there was statistically significant difference among the forty-nine genotypes for most of the traits studied except root volume and root dry weight. The highest heritability value was recorded for total nodules per plant followed by effective nodules per plant and plant height. Significant wide range of mean values was observed in all the characters evaluated. This indicates that the characters can be improved through selection. The Divergence analysis grouped the 49 soybean genotypes into five which shows crossing between genotypes which fall in to different classes would result in hybrid vigour. The principal component analysis revealed that 6 components have accounted for $79.90 \%$ of the total variation among the genotypes.
\end{abstract}

Keywords: Divergence Analysis, Genetic Variability, Genetic Advance, Heritability, Principal Component Analysis

\section{Introduction}

The magnitude of genetic variability present in a population of any crop species is central to crop improvement which must be exploited by plant breeders for yield improvement. Soybean is economically important and genetically diverse cultivated species. Because the crop is grown in diverse agro-ecological environments, variation in genetic constitution do exist among the various genotypes. This implies the potential for utilizing such variability in crop improvement programs. Soybean (Glycine max (L.) Merrill) belongs to the family Leguminacae, subfamily Papilionoideae, tribe phaseolae, and genus Glycine. It is reported to be domesticated in Asia, probably in north eastern China about 2500 B. C. [13]. Since then, it has spread to different countries in the world and became an established component of world agriculture. According to Agricultural Sample Survey of Ethiopia [2], there are 49,642 private peasant holdings that cultivate about $6,352.5$ hectares of land and produced 58,489.5 quintals of soybean. The average production therefore, is 9.21 quintals per hectare. In other words, the level of production per peasant holding has been 1.18 quintals. At present the use of soybean in Ethiopia is limited to baby foods production. These baby food processing plants such as Faffa Food Factory mainly covers their demand totally from imports as there is no ample and sustainable supply of soybean required by the factories. Soybean breeding in Ethiopia was started in the 1950s on evaluation of introduced varieties with main emphasis of replacing soybean flour import with locally produced soybean flour and introducing the crop in to the existing crop production system and in the diet of the poor farmers [1]. During the last 45 years, a large number of soybean introductions with varying maturity duration were evaluated for adaptation, yield potential and desirable agronomic characters at several locations ranging from 300 to 2,200 
m.a.s.l. in the country. As a result, varieties suitable for production in the country were recommended or released for general cultivation. This research is therefore undertaken with the objective of estimate the extent of phenotypic and genotypic variability, heritability and the genetic advance expected under selection.

\section{Materials and Methods}

An investigation study was carried out at Jimma Agricultural Research Center, Jimma, Ethiopia. Forty nine soybean genotypes of diverse genetic origin were evaluated for their genetic parameters. The materials were sown out to the field in simple lattice design with two replications on the main cropping season of 2012 .

\subsection{The Experimental Site}

The experiment was conducted at Jimma Agricultural Research Center of Ethiopian Institute of Agricultural Research. It is geographically located at $7^{0} 40^{\prime} 9^{\prime} \mathrm{N}$ latitude and $36^{\circ} 47^{\prime} 6$ 'E longitude at elevation of $1,753 \mathrm{~m}$. a. s. 1 . in south western part of Ethiopia. It is categorized under tepid to cool sub-humid sub agro-ecology zone of the country. The average annual rainfall is $1,559 \mathrm{~mm}$. The maximum and minimum temperatures are $26.2^{\circ} \mathrm{C}$ and $11.3^{\circ} \mathrm{C}$, respectively. The major soil types of the area are chromic Nitosols and Cambisols in the uplands, whereas Fluvisol is the dominant soil type in the bottom land and almost all soil types have $\mathrm{pH}$ less than 5 .

\subsection{Experimental Design and Management}

The experiment was laid out in a 7X7 simple lattice design with two replications. The plot size was three rows of $4 \mathrm{~m}$ length with $0.6 \mathrm{~m}$ row spacing i.e. $4 \mathrm{~m} \times 0.6 \mathrm{~m}=4.8 \mathrm{~m}^{2}$.

In order to facilitate the nitrogen fixation process of the roots, rhizobia bacteria (Rhizobium japonicum) were incorporated into the soil uniformly.

\subsection{Data Analyses}

The data were subjected to statistical analysis of variance as per the simple lattice design for each character by the GLM and ANOVA procedures of SAS [15]. Efficiency of the simple lattice design relative to RCBD was checked and in most of the traits studied the lattice design was found to be more efficient than that of the RCBD. Least Significant Difference (LSD) was used to separate the means.

\section{Results and Discussion}

\subsection{Mean, Range and Estimates of Genetic Parameters}

Range and mean values of the 15 characters are shown in Table 1. The 49 soybean genotypes showed wide range of variability for all characters; except pod length and root dry weight. The highest grain yield $(3,868 \mathrm{~kg} / \mathrm{ha})$ was recorded from TGX-297-6E-1 followed by G01892 (3,735kg/ha) which were higher than the grand mean of the genotypes studied $(2,160.00 \mathrm{~kg} / \mathrm{ha})$. While low yield $(795 \mathrm{~kg} / \mathrm{ha})$ was obtained from the genotype PR-160-6.

Table 1. Range, mean, variance, broad sense heritability, genotypic and phenotypic coefficient of variation and genetic advance as per cent of mean for characters of soybean genotypes.

\begin{tabular}{|c|c|c|c|c|c|c|c|c|c|c|}
\hline Characters & Range & Mean \pm S.E Mean & $\sigma^{2} \mathrm{~g}$ & $\sigma^{2} \mathbf{e}$ & $\sigma^{2} \mathbf{p}$ & GCV (\%) & PCV (\%) & $\mathbf{H}^{2}(\%)$ & GA & GA (\%) \\
\hline $\mathrm{DF}$ & $46.00-86.00$ & $64.20 \pm 2.55$ & 43.79 & 7.26 & 51.05 & 10.30 & 11.12 & 85.77 & 12.82 & 19.97 \\
\hline DPS & $57.00-97.00$ & $75.62 \pm 2.39$ & 44.95 & 5.66 & 50.61 & 8.86 & 9.40 & 88.81 & 13.47 & 17.81 \\
\hline DM & $111.00-148.00$ & $125.74 \pm 2.69$ & 42.89 & 8.04 & 50.93 & 5.20 & 5.67 & 84.21 & 13.08 & 10.40 \\
\hline PH & $37.00-120.00$ & $76.78 \pm 4.23$ & 240.51 & 14.97 & 255.48 & 20.20 & 20.81 & 94.14 & 32.04 & 41.73 \\
\hline PPP & $26.00-79.00$ & $46.43 \pm 4.00$ & 137.30 & 14.95 & 152.25 & 25.23 & 26.57 & 90.18 & 23.70 & 51.02 \\
\hline PL & $3.00-5.00$ & $4.10 \pm 0.22$ & 0.24 & 0.05 & 0.29 & 11.83 & 13.03 & 82.45 & 0.93 & 22.64 \\
\hline BY & $19.00-51.00$ & $32.99 \pm 3.22$ & 62.48 & 11.07 & 73.55 & 23.96 & 26.00 & 84.94 & 16.20 & 49.11 \\
\hline TNPP & $13.00-98.00$ & $31.53 \pm 1.88$ & 175.92 & 3.42 & 179.34 & 42.07 & 42.47 & 98.09 & 27.72 & 87.91 \\
\hline ENPP & $7.00-66.00$ & $21.18 \pm 1.91$ & 104.64 & 3.58 & 108.22 & 48.28 & 49.10 & 96.69 & 21.20 & 100.06 \\
\hline RDW & $2.00-5.00$ & $2.92 \pm 0.66$ & 0.11 & 0.48 & 0.59 & 11.35 & 26.30 & 18.64 & 0.31 & 10.67 \\
\hline RV & $4.00-16.00$ & $8.02 \pm 2.01$ & 0.37 & 4.85 & 5.22 & 7.58 & 28.48 & 7.08 & 0.87 & 10.81 \\
\hline RBR & $4.34-16.00$ & $8.93 \pm 1.96$ & 2.67 & 3.83 & 6.50 & 18.27 & 28.53 & 41.03 & 2.99 & 33.51 \\
\hline HSW & $8.00-22.00$ & $12.35 \pm 1.97$ & 2.72 & 3.93 & 6.65 & 13.35 & 20.88 & 40.86 & 2.28 & 18.46 \\
\hline GY & $795.00-3868.00$ & $2160.12 \pm 14.09$ & 399246.81 & 189.18 & 399436.00 & 29.25 & 29.26 & 85.95 & 1428.4 & 66.14 \\
\hline
\end{tabular}

$\mathrm{DF}=$ Days to $50 \%$ flowering, DPS=Days to $50 \%$ pod setting, DM=Days to maturity, $\mathrm{PlH}=\mathrm{Plant}$ height, $\mathrm{PPP}=\mathrm{Pod}$ per plant, $\mathrm{PL}=\mathrm{Pod}$ length, $\mathrm{BY}=\mathrm{Biomass}$ yield, TNPP=Total nodules per plant, ENPP=Effective nodules per plant, RV=Root volume, RDW= Root dry weight, RBR=Root to biomass ratio, HSW=Hundred seed weight, $\mathrm{HI}=$ Harvest index, $\mathrm{GY}=$ Grain yield. S.E. Mean $=$ Standard error of the mean, $\sigma^{2} \mathrm{~g}=$ Genotypic variance, $\sigma^{2} \mathrm{e}=$ Environmental variance, $\sigma^{2} \mathrm{p}=$ Phenotypic variance, $\mathrm{H}^{2}(\%)=$ Broad sense heritability,

GCV $(\%)=$ Genotypic coefficient of variation, PCV $(\%)=$ Phenotypic coefficient of variation, $(\%)$ ECV= Environmental coefficient of variation, GA= Genetic advance, GA $(\%)=$ Genetic advance as per cent of mean.

About 57.14 per cent of the genotypes gave above the grand mean of grain yield. If the breeding objective is to improve seed yield, genotypes with high yield in this study need further investigation. The characters such as plant height, pod number per plant, total nodules per plant, effective nodules per plant, biomass yield, root dry weight 
and harvest index showed higher values at with mean of $76.79 \mathrm{~cm}, 46.44,31.53,18.29,32.99 \mathrm{~g}, 8.02 \mathrm{~g}$, and 38.12 , respectively. The genotype 601853 scored the highest plant height $(118.17 \mathrm{~cm})$. Therefore, when breeding for higher plant height this genotype should be considered. PR-160-6 scored the highest pod number per plant (79.00) indicating it could be the preferable genotype in breeding for high number of pods per plant.

\subsection{Estimates of Variance Components}

grain yield, biomass yield, number of pods per plant, plant height, total nodules per plant, effective nodule per plant, days to $50 \%$ flowering, days to pod setting, days to maturity and harvest index exhibited high genotypic and phenotypic variances. Phenotypic coefficients of variation (PCV) values ranged from $5.67 \%$ for days to maturity to $49.10 \%$ for effective nodules per plant, whereas the genotypic coefficients of variation (GCV) ranged from $5.20 \%$

for days to maturity to $48.28 \%$ for effective nodules per plant. In addition, PCV values were generally higher than their corresponding GCV values for all the characters considered indicating the importance of environment in the expression of these traits.

According to [3], PCV and GCV values greater than $20 \%$ are regarded as high, whereas values less than $10 \%$ are considered to be low and values between $10 \%$ and $20 \%$ to be medium. Based on this delineation, PCV and GCV values were high for grain yield, biomass yield, number of pods per plant, plant height, total nodules per plant, effective nodules per plant, and harvest index. It indicates that selection may be effective based on these characters and there phenotypic expression would be a good indication of genetic potential. The PCV and GCV values were medium for pod length, and days to $50 \%$ flowering. The low PCV and GCV values were obtained for days to pod setting and days to maturity indicating lack of adequate variability for these traits which hinders the breeding work for the improvement of these traits.

\subsection{Estimation of Broad-Sense Heritability and Genetic Advance}

Estimates of heritability in broad sense ranged from $7.08 \%$ for root volume to $98.09 \%$ for total nodule per plant (Table 1). All the characters except root dry weight, root volume, root to biomass ratio and hundred seed weight had high to very high heritability. The magnitudes of heritability for most of the quantitative characters were moderate to high, except the low heritability of root dry weight and root volume. Genetic advance as percent of mean ranged from 10.48 for days to maturity to 100.06 for effective nodules per plant (Table 5). At this location relatively high genetic advance as percent of mean was recorded for effective nodules per plant $(100.06 \%)$, total nodules per plant $(87.91 \%)$, grain yield $(66.14 \%)$, pod number per plant $(51.02 \%)$, biomass yield $(49.11 \%)$, harvest index $(48.80 \%)$, plant height $(41.73 \%)$, root to biomass ratio (33.51\%) and pod length (22.64\%). Medium genetic advance as percent of mean was recorded for days to $50 \%$ flowering $(19.97 \%)$, hundred seed weight (18.46), days to pod setting (17.81\%), root volume (10.81\%), root dry weight $(10.67 \%)$ and days to maturity $(10.40 \%)$.

\subsection{Cluster Analysis}

Divergence analysis is a technique used to categorize genotypes that are similar into one group and others into a different group. D-square statistics $\left(\mathrm{D}^{2}\right)$ developed by Mahalanobis [7], has been used to classify the divergent genotypes into different groups. The genetic improvement through hybridization and selection depends upon the extent of genetic diversity between parents.

The genotypes were grouped in to five distinct clusters (Table 2). This indicates the tested soybean genotypes were moderately divergent. The genotypes were distributed in such a way that $21(42.85 \%)$ genotypes were grouped into Cluster I, $14(28.57 \%)$ genotypes into Cluster III, 8 (16.32\%) genotypes into Cluster II, $4(8.16 \%)$ genotypes into cluster IV and $2(4.08 \%)$ genotypes into cluster V.

Table 2. The distribution of genotypes into five clusters based on $D^{2}$ analysis for the 49 soybean genotypes.

\begin{tabular}{lll}
\hline Cluster & Number of genotypes & Genotypes included \\
\hline I & 21 & $\begin{array}{l}\text { IAC-11, H10, G01892, H5, AGS-7-1, G9945, F81-7636-4, JSL1, AGS-3-1, AGS-234, AGS-299-2, PR-145-2, IAC- } \\
\text { 6, Essex-1, H2, V1-1, H1, Promoveria, H4, SR-4-3, HS-82-2136 }\end{array}$ \\
II & 8 & PR-41(339), IAC-73-5115, Assosa local check 1, G03705, TGX-1895-49-F, H18, Protana, PR-160-6 \\
III & 14 & Lotus, Clark 63k, PR-149-81-EP, G01853, H14, F82-7629-2, G00391, H3, FB1-7636, G00386, Crowford, PR-143- \\
IV & 4 & $(14)$, SR-4-1, TGX-1895-33F \\
V & 2 & AGS-3, G00141, Davis, AGS-214 \\
\hline
\end{tabular}

Table 3. Cluster mean for the 15 characters studied.

\begin{tabular}{|c|c|c|c|c|c|}
\hline Traits & Cluster I & Cluster II & Cluster III & Cluster IV & Cluster V \\
\hline Days to $50 \%$ flowering & 64.29 & $73.00 * *$ & 64.07 & 62.75 & $55.00 *$ \\
\hline Days to pod setting & 72.00 & $83.88 * *$ & 73.18 & 71.50 & $71.00 *$ \\
\hline Days to maturity & 123.90 & $136.53 * *$ & 124.44 & 123.02 & $119.65^{*}$ \\
\hline Plant height & 73.91 & $92.07 * *$ & $72.66^{*}$ & 75.20 & 77.89 \\
\hline Pod number per plant & 44.55 & $58.50 * *$ & 46.07 & 57.00 & $39.50 *$ \\
\hline Pod length & $4.27 * *$ & 3.88 & 4.11 & $3.69 *$ & 3.85 \\
\hline
\end{tabular}




\begin{tabular}{|c|c|c|c|c|c|}
\hline Traits & Cluster I & Cluster II & Cluster III & Cluster IV & Cluster V \\
\hline Total nodules per plant & 31.10 & $23.94 *$ & 34.29 & $42.38 * *$ & 25.50 \\
\hline Effective nodules per plant & 16.86 & 16.25 & 16.79 & $37.50 * *$ & $13.50 *$ \\
\hline Root volume & 7.69 & 8.06 & $8.93 * *$ & 7.38 & $6.25 *$ \\
\hline Root dry weight & 2.85 & $2.90 * *$ & $2.64 *$ & 2.88 & 2.75 \\
\hline Root to biomass ratio & 9.40 & 8.83 & $7.97 *$ & $10.08 * *$ & 8.89 \\
\hline Hundred seed weight & $12.75 * *$ & 11.88 & 12.36 & 12.57 & $11.00 *$ \\
\hline Grain yield & 2480.00 & $1158.40 *$ & 1746.40 & 3115.30 & $3794.50 * *$ \\
\hline
\end{tabular}

$* *=$ highest value and $*=$ lowest value

\subsection{Genetic Distance Between Clusters}

The pair wise generalized squared distance $\left(\mathrm{D}^{2}\right)$ among clusters is depicted in table 3 .

The $\chi^{2}$-test for the five clusters (Table 3 ) indicated that there was statistically significant difference among the clusters except between cluster I and III (22.65). The maximum distance was found between cluster II and cluster $\mathrm{V}\left(\mathrm{D}^{2}=305.26\right)$ followed by cluster III and cluster V $\left(\mathrm{D}^{2}\right.$ $=179.31)$, cluster II and cluster IV $\left(D^{2}=162.82\right)$, cluster III and cluster IV $\left(D^{2}=90.35\right)$, cluster I and cluster V $\left(D^{2}\right.$ $=87.13)$, cluster I and cluster II $\left(D^{2}=77.19\right)$ and cluster IV and cluster $\mathrm{V}\left(\mathrm{D}^{2}=60.58\right)$. Increasing parental distance implies a great number of contrasting alleles at the desired loci, and then to the extent that these loci recombine in the F2 and F3 generation following a cross of distantly related parents, the greater will be the opportunities for the effective selection for yield factors.

Crosses involving parents belonging to most divergent clusters are expected to manifest maximum genetic recombination and variation in genetic architecture (Singh et al., 1987). For instance, in the present result, crosses involving parents belonging to most divergent clusters, for example clusters V with cluster II, cluster V with cluster III, and cluster IV with cluster II are expected to provide relatively better genetic recombination and combination in their progenies. However, the selection of parents should also consider the special advantages of each cluster and each genotype within a cluster depending on specific objectives of hybridization.

In most of the cases, genotypes collected from same place of origin fell in to the different clusters and from different places of origin fell in to same cluster.

Regarding to genotypes collected from Ethiopia, at Jimma, those genotypes from Awassa area are distributed in to cluster I $(47.36 \%)$ and the rest of the genotypes were distributed in to cluster II to cluster V each cluster having $10.52 \%$ of the genotypes. Genotypes from Pawe area are also distributed in to different clusters at Jimma. For instance, $40 \%$ of the genotypes are in cluster III, $30 \%$ in cluster II, $20 \%$ in cluster I and $10 \%$ in cluster IV. The genotypes from Jimma area are distributed in cluster III and cluster IV each having $66.66 \%$ and $33.34 \%$, respectively. The genotype from Assosa area is found in cluster II.
Table 4. Mahalanobis distance between groups of soybean genotypes.

\begin{tabular}{llllll}
\hline CLUSTERS & I & II & III & IV & V \\
\hline I & - & $77.19^{* *}$ & $22.65^{\text {ns }}$ & $30.65^{* *}$ & $87.13^{* *}$ \\
II & & - & $27.17^{*}$ & $162.82^{* *}$ & $305.26^{* *}$ \\
III & & & - & $90.35^{* *}$ & $179.31^{* *}$ \\
IV & & & & - & $60.58^{* *}$ \\
V & & & & & - \\
\hline
\end{tabular}

$\chi^{2}=23.68$ and 29.14 at $5 \%, 1 \%$ probability level respectively.

$*$, ** Significant at 0.05 and 0.01 probability levels, respectively.

\section{Conclusion}

Based on the relative squared distance values $\left(\mathrm{D}^{2}\right)$ between any two genotypes, the 49 soybean genotypes were grouped into five distinct clusters. This indicates that the soybean genotypes were moderately divergent.

The present study generally implied the presence of significant genetic variability among the tested genotypes. Thus, there is an opportunity to bring about improvement through direct selection or hybridization. However, all the above conclusions were derived from results of studies conducted within one season. So, further studies of soybean genotypes with larger sample size in broad environments and seasons should be conducted on soybean variability in order to give confirmative results.

The principal component analysis at revealed six principal components (PCs) having eigenvalues between 1.17 and 4.20 extracted a cumulative of about $79.90 \%$ of the total variation noted among the genotypes. It was also noted that differentiation of the genotypes into different cluster was because of a cumulative effect of a number of characters rather than the small contribution of each character.

Phenotypic coefficient of variability (PCV) values ranged from $5.67 \%$ for days to maturity to $49.10 \%$ for effective nodules per plant, whereas the genotypic coefficient of variability (GVC) ranged from $5.20 \%$ for days to maturity to $48.28 \%$ for effective nodules per plant. Phenotypic coefficient of variability values were low for days to pod setting, and days to maturity; medium for pod length and days to $50 \%$ flowering and it was high for the rest of the characters. Genotypic coefficient of variability values were low for days to pod setting, days to maturity, and root volume; high for grain yield, biomass yield, number of pods per plant, hundred seed weight, plant height, total nodules per plant, effective nodules per plant, and harvest index.

The high GVC values of these characters suggest the 
possibility of improving these traits through selection.

\section{References}

[1] Asrat A.; Abush T.; Sentayehu A. and Mulugeta A. Food and Forage Legumes of Ethiopia: Progress and Prospects. Proceedings of the Workshop on Food and forage Legumes, 22 - 26 September 2003. Addis Ababa, Ethiopia.

[2] CSA., 2014. Agricultural sampale survey 2013/14. Report on Area and Production of Major Crops (Private Peasant Holdings, Meher Season), Vol. I, Statistical Bulletin 532, Central Statistics Agency, Addis Ababa, pp: 1-124.

[3] Deshmukh, S. NS. S, M. S. Basu and P. S. Reddy, (1986). Genetic variability, character association and path coefficient analysis of quantitative traits in Vignia bunch varieties of ground nut. Indian jour. Agri. Sci. 56: 515-518.

[4] Gutu, B., 2015. Genetic variability and path coefficient analysis for yield and yield related traits in common bean (Phaseolus vulgaris L.). M. Sc. Thesis, Haramaya University, Hararge, Ethiopia.

[5] Jollife, I. T (1986) Principal component analysis, New York: Springer.

[6] Kausar H. (2005). Genetic investigations in segregating populations of soybean (Glycine $\max$ (L.) Merrill). M. Sc. (Agri.) Thesis, University of Agricultural Sciences, Dharwad.

[7] Mahalanobis, P. C., (1936). On the generalized distance in statistics. In : Proceedings of National Academy of Science (Indian), 2 : 49-55. Poehlman and Sleeper, 1995.

[8] Malik, M. F. A., A. S. Qureshi, M. Ashraf and A. Ghafoor. (2006). Genetic variability of the main yield related characters in soybean. Inter. Journ. Agri. \& Biol., 8 (6): 815-619.
[9] More, A. D. and A. T. Borkar, 2016. Analysis of genetic variability, heritability and genetic advance in Phaseolus vulgaris L. Int. J. Curr. Microbiol. Applied Sci., 5: 494-503.

[10] Narayan, J., 2013. Variability and correlation analysis in diverse genotypes of French bean (Phaseolus vulgaris L.). M. Sc. Thesis, Banaras Hindu University, Varanasi, India.

[11] Negash, K., 2006. Studies on genetic divergence in common bean (Phaseolus vulgaris L.) introductions of Ethiopia. M. Sc. Thesis, Addis Ababa University, Ethiopia.

[12] Prakash, J., R. B. Ram and M. L. Meena, 2015. Genetic variation and characters interrelationship studies for quantitative and qualitative traits in French bean (Phaseolus vulgaris L.) under Lucknow conditions. Legume Res.: Int. J., 38: 425-433.

[13] Poehlman, J. M. and D. A. Sleper, (1995). Breeding Field Crops. 4th ed. Iowa State University Press, Ames, Iowa 50014, USA.

[14] Sardana, S., R. K. Mahajan, N. K. Gautam and B. Ram, 2007. Genetic variability in pea (Pisum sativum L.) germplasm for utilization. SABRAO J. Breed. Genet., 39: 31-41.

[15] SAS Institute Inc., 2008. Statistical Analysis System, Version 9.2. Cary, North Carolina, USA.

[16] Soy Stats (2008). A reference guide to important soybean facts and figures. Available at http://www.soystats.com (verified 03/09/09).

[17] Spagnoletti, P. L. and C. O. Qualset, (1987). Geographic diversity for quantitative spike characters in a world collection of durum wheat. Crop sci. 27: 235-241. 